\title{
Activation of PAK2 by Serum Starvation Sensitizes its Response to Insulin Treatment in Adipocyte 3T3-L1 Cells
} Jun Ling ${ }^{1 *}$, Siska Corneillie ${ }^{2}$, Colby Cottell ${ }^{1}$ and Jolinda A Traugh ${ }^{2}$

${ }^{1}$ Department of Basic Sciences, The Commonwealth Medical College, 525 Pine Street, Scranton, PA 18509, USA

${ }^{2}$ Department of Biochemistry, University of California, Riverside, CA 92521, USA

\begin{abstract}
p21-activated kinase-2 (PAK2) is ubiquitously expressed in all mammalian cells and tissues tested so far. It is a unique member of PAK family kinases that can be activated by various stress conditions to induce apoptosis or cytostasis. Although many conditions have been reported to activate PAK2, serum starvation followed by insulin treatment has not been studied. In this study, pre-adipocyte (3T3-L1) sensitive to insulin signaling and important for energy homeostasis was used as the system to address this topic. It was found that serum starvation transiently activated PAK2 activity by about 3-fold within one hour, then returning to the basal level within three hours. Following the activation of PAK2 by serum starvation, insulin treatment resulted in a rapid deactivation of PAK2 through ubiquitination-proteasome mediated protein degradation. AKT1 and PAK2 activities were reversely related, suggesting that AKT1 activation could be a factor to initiate PAK2 degradation. This dynamic change of PAK2 by serum starvation and insulin was found to correlate with the fluctuation of protein synthesis, a major biological process that influences cell growth rate. Activation of PAK2 by serum starvation was correlated with about $50 \%$ inhibition of protein synthesis; subsequent treatment with insulin reversed this inhibition. Down-regulation of PAK2 by siRNA further proved that PAK2 was a causal factor leading to the inhibition of protein synthesis. In conclusion, this study identifies a new pattern of regulation of PAK2 by serum starvation and insulin, suggesting an important role of PAK2 in regulating adipocyte function in response to nutrient status and insulin signaling.
\end{abstract}

Keywords: P21-activated kinase-2 (PAK2); Signal transduction; Serum starvation; Insulin signaling; Protein synthesis

\section{Introduction}

p21-activated protein kinases (PAKs) are originally identified by binding to and activated by small GTPases Cdc42 and Rac1 [1,2]. A large amount of research has proved the important roles of PAKs in regulating cytoskeleton dynamics, cell motility, cell cycle, gene transcription and translation, and oncogenesis, etc. [3-5]. Among the six members of PAK family kinase, PAK1 is relatively well studied. It is a growth-promoting kinase that can be activated by insulin and serum [6,7]. PAK1 is also involved in carcinogenesis, especially as an important driver for breast cancer [8,9]. In contrast, PAK2 is a stressactivated kinase whose activity is stimulated by a large array of stresses, such as DNA damaging drugs [10], hyperosmolarity [11], irradiation [12], apoptotic stimuli (e.g. TNFa) [13]. The cytostatic activity of PAK2 has been proved by our previous study that the microinjection of active PAK2 into early frog embryos arrests cell cleavage [14]. Overexpression of PAK2 in HEK 293T, Cos7, and BALB 3T3 cells also induces cytostasis $[15,16]$. Under strong stress conditions, PAK2 is the only member of PAK family kinases that can be cleaved by caspase 3 to generate the C-terminal kinase domain (also called p34), thus becoming constitutively active to promote apoptosis $[17,18]$. On the other hand, PAK2 has been reported to have pro-survival function under certain activated status [19]. PAK2 can also be activated by transforming growth factor-beta (TGF- $\beta$ ) in a cell type-specific manner to mediate its effects on cell proliferation, differentiation, and migration [20,21]. With these diverse functions, we hypothesize PAK2 as a switch to regulate cell survival and death in response to various stress conditions. The importance of PAK2 is also reflected by a wide range of its substrates, including c-Myc [22], eIF4G [23], and the MAPK-interacting kinase1 (Mnk1) [24] etc.

Serum starvation is commonly used to inactivate kinases in cells prior to mitogenic treatments; it becomes a general practice in biochemical and cell biological research. Serum starvation also mimics a nutrient deprivation state in many tissues under various conditions, such as adipose tissue and the inner mass of tumor where the blood flow is limited [25]. Insulin as a multi-functional hormone plays critical roles in regulating energy homeostasis, cell growth, and cancer development $[26,27]$. The effects of serum and insulin converge on MAPK and PI-3 kinase/Akt/mTOR cell signaling pathways, leading to the regulation of protein synthesis as a major mechanism for their physiological functions [28]. Our previous study has identified that PAK2 down-regulates mRNA translation through phosphorylation of eIF4G1 and Mnk1 [23,24]. Thus, to expand our understanding on the function of PAK2 in these critical cell signaling pathways, we carried out this research to address the regulation of PAK2 by serum and insulin.

By using 3T3-L1 pre-adipocyte as a cellular system sensitive to serum starvation and insulin signaling, we analyzed the effects of serum starvation and insulin treatment on PAK2 activity. Our results showed that PAK2 was transiently activated by serum starvation; such activated PAK2 became more sensitive to the degradation by insulin treatment, which was mediated by ubiquitination-proteasome pathway. However, the serum-fed PAK2 was not affected by insulin treatment This dynamic change of PAK2 activity was found to correlate with the rate of protein synthesis. Overall, the results from this study expand our understanding about the role of PAK2 in nutrient and mitogen fluctuating conditions.

*Corresponding author: Jun Ling, Department of Basic Sciences, The Commonwealth Medical College, 525 Pine Street, Scranton, PA 18509, USA; Tel: 570-504-9644; Fax: 570-504-9618; E-mail: jling@tcmc.edu

Received: May 17, 2016; Accepted: June 09, 2016; Published June 13, 2016

Citation: Ling J, Corneillie S, Cottell C, Traugh JA (2016) Activation of PAK2 by Serum Starvation Sensitizes its Response to Insulin Treatment in Adipocyte 3T3L1 Cells. Biochem Anal Biochem 5: 277. doi:10.4172/2161-1009.1000277

Copyright: (c) 2016 Ling J, et al. This is an open-access article distributed under the terms of the Creative Commons Attribution License, which permits unrestricted use, distribution, and reproduction in any medium, provided the original author and source are credited. 


\section{Materials and Methods}

\section{Materials}

DMEM media and methionine-free DMEM media were purchased from ThermoFisher Scientific/Gibco. Insulin was from Eli Lily, and the proteasome inhibitor LLnL (N-Acetyl-Leu-Leu-Nle-CHO) was from Biomol Laboratories. [ $\left.\gamma^{-32} \mathrm{P}\right]$-ATP was from Amersham Corporation, and $\left.{ }^{35} \mathrm{~S}\right)$-methionine from Perkin Elmer Life Sciences. Histone (H4) and myelin basic protein (MBP) were from Sigma. FuGENE 6 transfection reagent was from Roche Applied Science. The pSilencer1.0-U6 vector was from Ambion. Protein A/G-agarose beads, PAK2 antibodies, and HRP-conjugated secondary antibodies were from Santa Cruz Biotechnology. Anti-ubiquitin antibody was from Zymed. Total AKT1 and Phospho-AKT1 (Ser473) antibodies were from Cell Signaling Technology. The ECL detection kit was from Pierce Protein Biology.

\section{Cell culture and treatment}

3T3-L1 mouse pre-adipocytes were purchased from ATCC and cultured in DMEM media supplemented with $10 \%$ fetal calf serum. Serum starvation was performed by washing the cells twice with serumfree medium, followed by the incubation in serum-free medium for the time periods indicated. Insulin $\left(10^{-8} \mathrm{M}\right)$ was used to treat the cells after serum-starvation.

\section{Preparation of cell lysate}

Cells after treatments were collected by washing twice with cold PBS, followed by cell lysis using RIPA buffer $(50 \mathrm{mM}$ Tris- $\mathrm{HCl}, \mathrm{pH}$ 8.0, $150 \mathrm{mM} \mathrm{NaCl}, 1 \% \mathrm{NP}-40,0.5 \%$ deoxycholate, and $0.1 \% \mathrm{SDS}$ ) supplemented with fresh protease (Set III, EMD) and phosphatase (Set III, EMD) inhibitor cocktails. After incubation for 15 min on ice, the cell extract was centrifuged at $16,000 \mathrm{~g}$ for $10 \mathrm{~min}$ at $4^{\circ} \mathrm{C}$, and the supernatant was taken as the total cell lysate. Protein concentration was measured using Bradford reagent.

\section{Immunoprecipitation (IP)}

Protein A/G-agarose beads ( $30 \mu$ slurry) were pre-incubated with $1 \mu \mathrm{g}$ of PAK2 antibody (N19) for $1 \mathrm{hr}$ at $4^{\circ} \mathrm{C}$, washed twice with RIPA buffer, and then incubated with $100 \mu \mathrm{g}$ of cell lysate for $2 \mathrm{hrs}$ at $4^{\circ} \mathrm{C}$. The immunoprecipitated complex was collected by centrifugation and washed three times with RIPA buffer for Western blot analysis, or washed twice with kinase reaction buffer for PAK2 activity assay.

\section{Pak2 activity assay}

Immunoprecipitated PAK2 was used for activity assay. The reaction was carried out for $30 \mathrm{~min}$ at $30^{\circ} \mathrm{C}$ in a final volume of 20 $\mu \mathrm{l}$ buffer containing $50 \mathrm{mM}$ Tris- $\mathrm{HCl}, \mathrm{pH} 7.4,10 \mathrm{mM} \mathrm{MgCl}, 30 \mathrm{mM}$ $\beta$-mercaptoethanol, $0.2 \mathrm{mM}\left[\gamma^{-}{ }^{32} \mathrm{P}\right] \mathrm{ATP}$ (specific activity $2000 \mathrm{cpm} /$ pmol), and $2 \mu \mathrm{g}$ of $\mathrm{H} 4$ or MBP as the substrate [29]. The reaction was terminated by SDS-loading buffer and analyzed by SDS-PAGE. The gel was stained by Coomassie blue and dried for autoradiography. The radioactive bands corresponding to $\mathrm{H} 4$ or MBP were excised for the quantitation by scintillation counter.

\section{Measurement of protein synthesis rate}

Exponentially growing 3T3-L1 cells treated by various conditions were labelled with $\left.{ }^{35} \mathrm{~S}\right)$-methionine $(10 \mu \mathrm{Ci} / \mathrm{ml})$ in methionine-free DMEM media to measure protein synthesis rate in vivo. The cells were washed twice with cold PBS and lysed with RIPA buffer in the presence of protease and phosphatase inhibitors as described above. Equal amount of cell extract $(100 \mu \mathrm{g})$ was precipitated by $10 \%$ trichloroacetic acid, followed by washing twice with $10 \%$ trichloroacetic acid and acetone and once with 95\% EtOH. The pellet was dried for the quantitation of radioactive incorporation by scintillation counter.

\section{Knockdown of PAK2 by siRNA}

PAK2 (human U24153) siRNA constructs were made by subcloning several regions of PAK2 cDNA into pSilencer1.0-U6 vector. The confirmed construct with DNA sequence encoding amino acid 197216 region of PAK2 was used in this experiment. 3T3-L1 cells at $40 \%$ confluency were co-transfected with the luciferase reporter $(0.5 \mu \mathrm{g})$ and pSilencer1.0 vector or the PAK2 siRNA/pSilencer 1.0 construct $(5 \mu \mathrm{g})$ using FuGENE 6. Thirty-six hours later, the cells were harvested and extracted to measure the translation rate through luciferase reporter assay [30].

\section{Statistical analysis}

All experiments in this study were repeated three times, and the data were presented as the means \pm standard deviation (SD). The difference between two comparable groups was analyzed by Student's $t$-test, and $P$-value of $<0.05$ was considered statistically significant.

\section{Results}

\section{Serum starvation activates PAK2 in 3T3-L1 cells}

To examine whether PAK2 can be activated by serum starvation, exponentially growing 3T3-L1 cells were deprived of serum over a time period of $5 \mathrm{hrs}$, and PAK2 activity was measured using immunoprecipitated PAK2. Both histone $\mathrm{H} 4$ and myelin basic protein (MBP) were used as the substrates to better evaluate PAK2 activity. As shown in Figure 1, the total protein amounts of PAK2 were not altered during the period of serum starvation (Figure 1A, upper panel). The double bands indicated the different phosphorylation states of PAK2, which are common for many other kinases. However, the PAK2 activities were changed as revealed by the kinase activity assay (Figure 1A, lower panel). MBP and histone H4 substrates showed slight difference, but the pattern of PAK2 activity change in response to serum starvation was the same. After the quantitation, it was found that PAK2 activity was increased by 2.0-2.5-fold at $1 \mathrm{hr}$-time point, followed by a phase of decrease of PAK2 activity. At $5 \mathrm{hr}$-time point PAK2 activity was increased again by 1.5 -fold (Figure 1B). This dual phase of PAK2 activation by serum starvation suggested an intriguing regulatory mechanism that might be similar to the oscillation of NFkB activation by TNFa [31]. To further confirm the activation of PAK2 by serum starvation, phosphorylation at Thr402 site as a signature of activated PAK2 was examined by Western blot. It was found that the phosphorylation of Thr402 was increased from 0.5-1.5 hrs of serum starvation; another increase at $5 \mathrm{hrs}$ was also observed (Figure 1C), consistent with the actual kinase activity assay shown in Figure 1B. Thus, it can be concluded that this rapid activation of PAK2 by serum starvation is due to the change of phosphorylation rather than the change of protein amount of PAK2.

\section{Effects of serum and insulin on serum starvation-activated PAK2}

After the activation of PAK2 by serum starvation, it is interesting to know how the activated PAK2 responds to growth or mitogenic stimuli, since this is a normal nutrient dynamics in vivo. Exponentially growing 3T3-L1 cells were serum-starved for $1 \mathrm{hr}$, followed by the treatment with serum or insulin for varied periods of time. The levels of PAK2 were then analyzed by immunoprecipitation and Western blot. 
It was found that insulin induced the degradation of serum starvation activated PAK2 rapidly, by the 30 min of treatment PAK2 was almost completely degraded (Figure 2A). Serum addition also down-regulated PAK2 but showed remarkable PAK2 degradation by 60 min (Figure 2B). In contrast, control PAK2 without serum starvation was not sensitive to the degradation by insulin, rather the protein was shifted to more upper band (Figure 2A, the most right lane), suggesting that PAK2 could be more active as the upper band generally representing the phosphorylated form. Hence, we identified a new phenomenon that activated PAK2 was more sensitive to the degradation induced by insulin or serum, which is consistent with the property of PAK2 as a stress-activated kinase that is stimulated by stress but deactivated by growth or pro-survival conditions.

To investigate the mechanism of PAK2 degradation induced by insulin, proteasome pathway was examined. As shown in Figure 2C, addition of proteasome inhibitor LLnL blocked the insulin-induced degradation of PAK2; meanwhile LLnL itself had no effect on the stability of PAK2. When the immunoprecipitated PAK2 was analyzed by Western blot using ubiquitin antibody, multiple bands of high molecular weight forms of PAK2 were detected under the treatment with LLnL; whereas no upper-shifted bands were detected when PAK2 was activated by serum starvation but not treated by insulin (Figure 2D). As a control, pre-immune IgG was used to replace PAK2 antibody

A

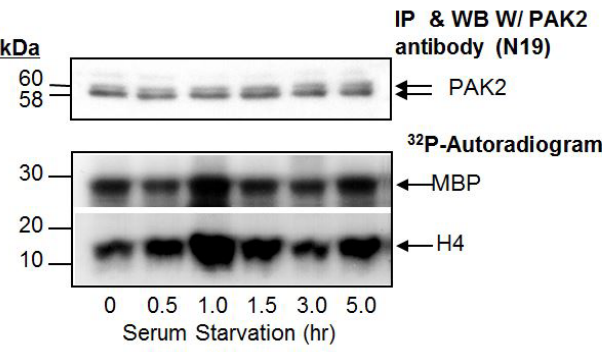

B

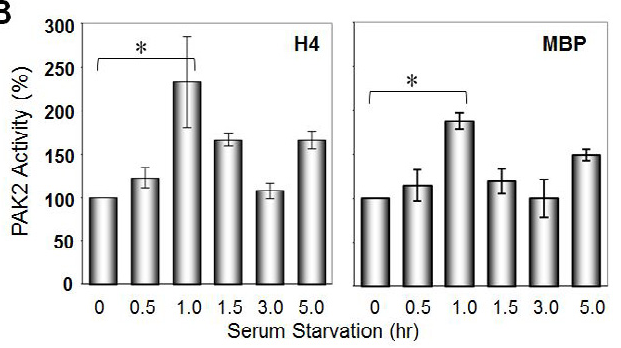

C

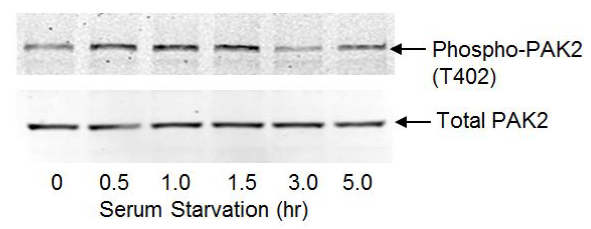

(A) Exponentially growing 3T3-L1 cells were used for serum starvation equal protein amounts of cell lysate were used for immunoprecipitation. Immunoprecipitated PAK2 was then used to measure the kinase activity using $\mathrm{H} 4$ and MBP as the substrates. Upper panel: immunoprecipitated PAK2 protein was confirmed by Western blot. Lower panel: Phosphorylation of $\mathrm{H} 4$ and MBP by PAK2 was visualized by autoradiography. (B) The phosphorylated $\mathrm{H} 4$ and MBP bands from the lower panel of $(A)$ were excised from the gel for the quantitation of ${ }^{32} \mathrm{P}$ incorporation. The data were the mean of three repeated experiments with standard deviations indicated by error bars. ${ }^{*}$, indicating significant difference with $P<0.05$. (C) Equal amount of cell lysate was probed by phospho-PAK2 antibody (Thr402) to evaluate the activation of PAK2.

Figure 1: PAK2 is activated by serum starvation.
A

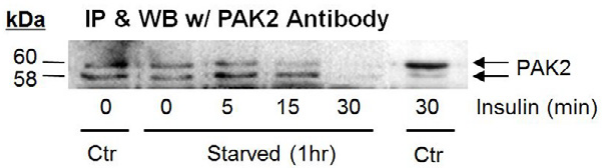

B

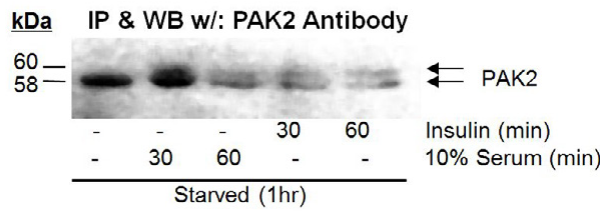

C

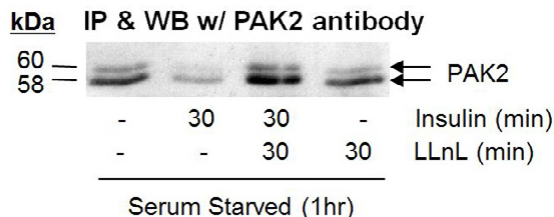

D

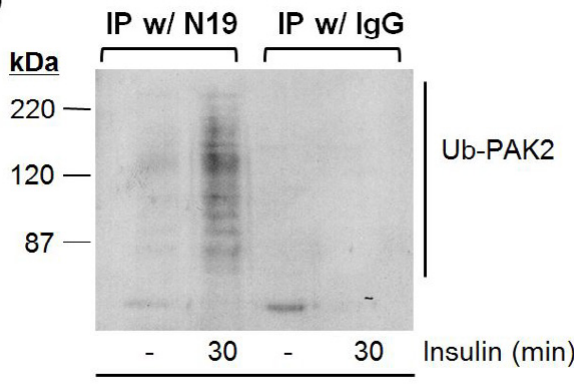

Serum Starved $(1 \mathrm{hr})+\mathrm{LLnL}(30 \mathrm{~min})$

(A) Control (Ctr) and serum-starved 3T3-L1 cells were treated with insulin. The amounts of PAK2 were analyzed by immunoprecipitation (IP) and Western blot. (B) Serum-starved 3T3-L1 cells were subject to serum addition and insulin treatment, and then the amounts of PAK2 were detected by IP and Western blot. (C) 3T3-L1 cells were serum-starved followed by the treatment with insulin in the presence or absence of proteasome inhibitor $\mathrm{LLnL}(50 \mu \mathrm{M})$. PAK2 was then analyzed by IP and Western blot. (D) PAK2 was immunoprecipitated from $1200 \mu \mathrm{g}$ of cell lysate using PAK2 antibody or pro-immune lgG as a control. Western blot with ubiquitin antibody was performed to visualize the poly-ubiquitinated PAK2.

Figure 2: Serum starvation activated PAK2 is sensitive to insulin-induced degradation through ubiquitination pathway.

for the same experimental procedure, then no PAK2 and ubiquitinated PAK2 bands were detected, therefore ensuring the high quality of experiment. Thus, this result demonstrated that poly-ubiquitination and proteasome mediated protein degradation was the mechanism of down-regulation of activated PAK2 by insulin.

Insulin signaling initiates many downstream kinase pathways for its broad physiological functions, among which activation of AKT plays a major role in the metabolic function of insulin, whereas activation of MAPK is important for the mitogenic function of insulin $[26,28]$. To understand what initiates the proteasome-mediated degradation of PAK2 by insulin, we hypothesize that insulin signaling effector kinases are more likely to phosphorylate PAK2 and prime it for ubiquitination, similar to the phosphorylation initiated processing of NFkB1/p105 [32]. There are a number of reports that PAK1 regulates AKT1 activation [33,34] and AKT1 also phosphorylates PAK1 for activation $[35,36]$, indicating the mutual regulation between $\mathrm{AKT}$ and PAK kinases. However, it is not known whether AKT regulates PAK2 for activation or degradation. Thus, the activation of AKT1 and its 
relationship with PAK2 became a reasonable link to be examined in this study. When serum-starved 3T3-L1 cells were treated by insulin for $24 \mathrm{hrs}$, it was found that insulin down-regulated PAK2 initially but increased PAK2 recovery starting from 4 hrs of treatment (Figure 3), top first panel). Meanwhile, AKT1 activity was detected to respond to insulin treatment more rapidly than PAK2. AKT1 reached the highest activity at $0.5 \mathrm{hrs}$ and sustained at the high activity level up to $4 \mathrm{hrs}$; later on AKT1 activity started to decline. Furthermore, when PAK2 was repressed by serum treatment for $24 \mathrm{hrs}$ after the initial serum starvation for $1 \mathrm{hr}$, AKT1 showed very high activity (Figure 3, the most right lanes in top $1^{\text {st }}$ and $2^{\text {nd }}$ panels). Under serum starvation for $1 \mathrm{hr}$ only, PAK2 expressed high activity, whereas AKT1 was almost completely inactive (the most left lanes in top $1^{\text {st }}$ and $2^{\text {nd }}$ panels). In summary, PAK2 and AKT1 exhibited a reciprocal pattern in activity, suggesting that active AKT1 might phosphorylate PAK2 at certain

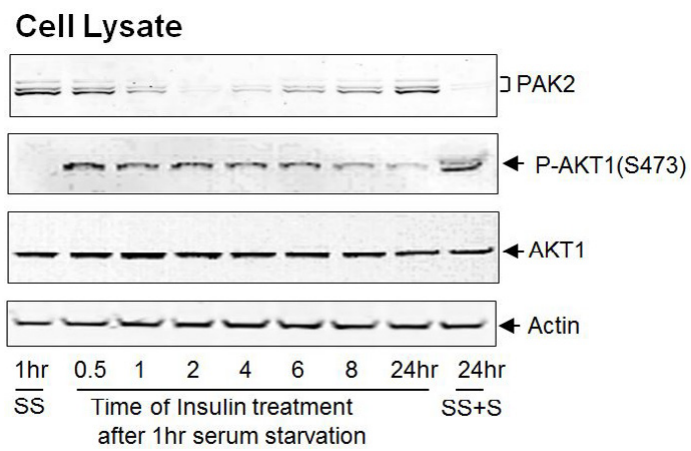

3T3-L1 cells at $50 \%$ confluency were serum-starved for $1 \mathrm{hr}$, and then treated with insulin for up to $24 \mathrm{hrs}$. One control sample was serum-starved for $1 \mathrm{hr}$ (SS); the other control was serum-starved for $1 \mathrm{hr}$ followed by the culture in complete media with serum (10\%) for $24 \mathrm{hrs}(\mathrm{SS}+\mathrm{S})$. Cell lysate was prepared and the equal amounts of protein $(75 \mu \mathrm{g})$ were analyzed by Western blot using different antibodies as indicated. The top panel is the amount of PAK2, and middle two panels are the phosphorylated and total amounts of AKT1 respectively.

Figure 3: The dynamic change of PAK2 is reversely related with AKT1 activity during serum starvation and insulin treatment.
A

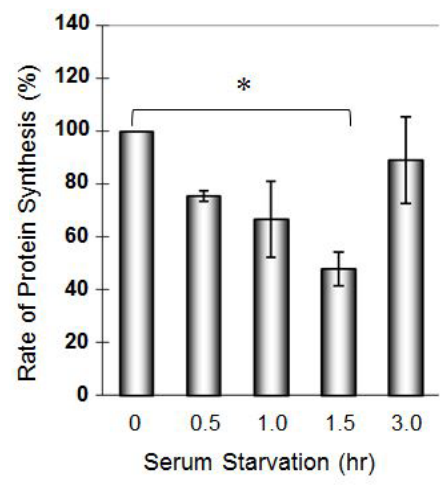

B

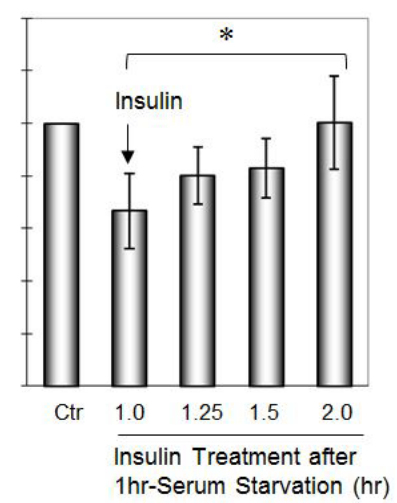

Exponentially growing 3T3-L1 cells were subjected to serum starvation and subsequent treatment with insulin, and the protein synthesis rate was measured as described in "materials and methods". (A) Protein synthesis rate under serum starvation. (B) Protein synthesis rate under insulin treatment after serum starvation for $1 \mathrm{hr}$. The data were the mean of three repeated experiments with standard deviations indicated by error bars. *, indicating significant difference with $P<0.05$.

Figure 4: The effects of serum starvation and insulin treatment on protein synthesis. site(s) and lead to its degradation by proteasome pathway.

\section{Regulation of protein synthesis by serum starvation and insu- lin is partially mediated by PAK2}

Activated PAK2 expresses a broad range of physiological functions. To better understand the function of the dynamic change of PAK2 by serum starvation and insulin on cell growth, protein synthesis was analyzed in this study. 3T3-L1 cells were serum-starved for up to $3 \mathrm{hrs}$, during which the protein synthesis rate was measured by in vivo labeling approach, so that the total endogenous protein synthesis rate can be accurately evaluated. The newly synthesized proteins were labeled with $\left.{ }^{35} \mathrm{~S}\right)$-methionine for $15 \mathrm{~min}$ prior to the collection of cell at each time point. It was found that serum starvation reduced protein synthesis rate gradually and reached the maximal inhibition by 1.5 hrs (Figure 4A), and then the protein synthesis rate was recovered to $\sim 90 \%$ of the control by the end of 3 hrs of serum starvation. This pattern of protein synthesis change was conversely related with the change in PAK2 activity (Figure 1), consistent with the inhibitory effect of PAK2 on protein synthesis as revealed by our previous study [23]. Treatment of the serum-starved cells with insulin resulted in a rapid and continuous recovery of protein synthesis rate. By the time of $2 \mathrm{hrs}$, protein synthesis rate was recovered to the control level (Figure $4 \mathrm{~B})$, suggesting that the degradation of PAK2 by insulin released its inhibition on protein synthesis.

To confirm if PAK2 directly contributes to the down-regulation of protein synthesis, the luciferase reporter gene was co-transfected into 3T3-L1 cells with PAK2 siRNA or vector control. The luciferase activity of vector control cells without treatments was set as $100 \%$ (Figure 5A). In the vector control cells, protein synthesis was inhibited by serum starvation and recovered by subsequent insulin treatment, showing the same pattern and rate as that in Figure 4A. When PAK2 was knocked down by siRNA, the response of protein synthesis to serum starvation and insulin treatment still showed a similar pattern, but less inhibited by serum starvation and less recovered by insulin treatment (Figure $5 \mathrm{~A}$, right three bars). The corresponding changes in PAK2 expression level (Figure 5B) were consistent with its inhibitory effect on protein synthesis as shown in Figure 5A, therefore confirming PAK2 as a causal factor that partially mediated the regulation of protein synthesis by serum starvation and insulin treatment in 3T3-L1 cells.

\section{Discussion}

This study reported a new mechanism of activation of PAK2 by serum starvation and subsequent degradation by insulin treatment in adipocytes. The activation of PAK2 by serum starvation was due to the increased phosphorylation; whereas the degradation of PAK2 by insulin was mediated by ubiquitination/proteasome pathway. It has been known that PAK kinases and insulin signaling are mutually regulated. PAK1 is identified to mediate insulin-induced GLUT4 translocation and glucose uptake in skeleton muscle cells, wherein insulin treatment activates PAK1 through PI3K/AKT signaling pathway [37,38]. PAK1 is also a mediator of glucose-stimulated insulin secretion in pancreatic $\beta$-cells [39]. However, PAK2 is negatively regulated by insulin in neural cells, wherein AKT1 is identified to be the kinase responsible for PAK2 phosphorylation [40]. These results are consistent with and support our findings in adipocytes. It is important to note that serum starvation primes or sensitizes the down-regulation of PAK2 by insulin. Such information is particularly interesting in adipose that is a peripheral tissue of insulin signaling and serves as an important site for energy metabolism. The results of this study also support our hypothesis that activated PAK2 might be more sensitive to degradation, which adds a 
A

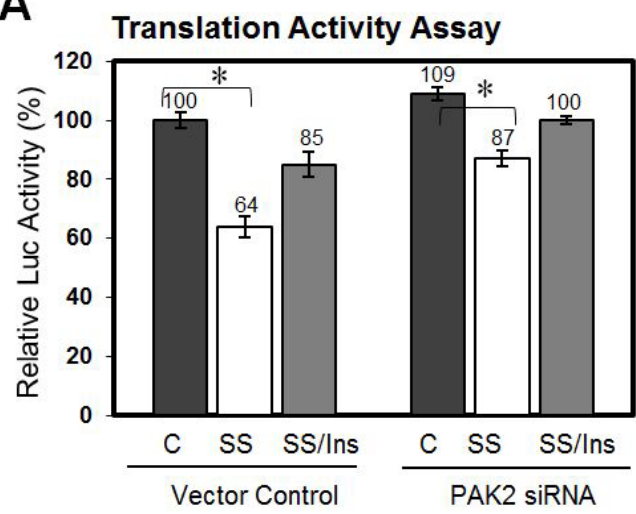

B
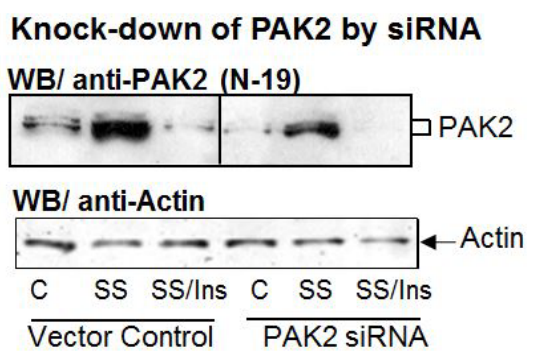

3T3-L1 cells at $40 \%$ confluency were co-transfected with the luciferase (Luc) reporter gene and the PAK2 siRNA/pSilencer1.0 construct or the vector control (pSilencer1.0). Thirty-six hours post transfection, the cell lysate was prepared and the translation activity was measured via Luc activity assay. (A) The translation activities were measured using Luc reporter assay. C: control; SS: serum starvation; SS/Ins: serum starvation (for $1 \mathrm{hr}$ ) followed by insulin treatment (for $30 \mathrm{~min}$ ). The data were the mean of three repeated experiments with standard deviations indicated by error bars. *, indicating significant difference with $P<0.05$. (B) The corresponding expression levels of PAK2 were detected by Western blot using the same cell lysates.

Figure 5: PAK2 mediates the effects of serum starvation and insulin on protein synthesis.

fine control on PAK2 activation under various conditions. Thus, this dynamic regulation of PAK2 by stress and growth conditions might be a mechanism underlying the potential role of PAK2 in pre-adipocyte differentiation and function.

Furthermore, this unique pattern of regulation of PAK2 might also play an important role in cancer development. Cancer cells constantly encounter various changes of stress and pro-survival conditions. The inner core of tumor is in a nutrient deprivation and hypoxia microenvironment, whereas metastatic cells in blood circulation are under serum-fed condition for progression. Some observations from this study, such as the dual phasic effect of serum starvation and the relationship between PAK2 and AKT, suggest the complicated regulation of PAK2 activation that will be a topic in our future study.

\section{Acknowledgements}

This research was supported by the start-up funds of The Commonwealth Medical College to JL and NIH grant (GM26738) to JAT. SC was supported in part by a Postdoctoral Fellowship from the California Breast Cancer Research Program.

\section{References}

1. Manser E, Leung T, Salihuddin H, Zhao ZS, Lim L (1994) A brain serine/ threonine protein kinase activated by Cdc42 and Rac1. Nature 367: 40-46.

2. Bagrodia S, Cerione RA (1999) Pak to the future. Trends Cell Biol 9: 350-355.
3. Bokoch GM (2003) Biology of the p21-activated kinases. Annu Rev Biochem 72: 743-781.

4. Molli PR, Li DQ, Murray BW, Rayala SK, Kumar R (2009) PAK signaling in oncogenesis. Oncogene 28: 2545-2555.

5. Radu M, Semenova G, Kosoff R, Chernoff J (2014) PAK signalling during the development and progression of cancer. Nat Rev Cancer 14: 13-25.

6. Chiang YA, Shao W, Xu XX, Chernoff J, Jin T (2013) P21-activated protein kinase 1 (Pak1) mediates the cross talk between insulin and ß-catenin on proglucagon gene expression and its ablation affects glucose homeostasis in male C57BL/6 mice. Endocrinology 154: 77-88.

7. Kameritsch P, Kiemer F, Beck H, Pohl U, Pogoda K (2015) Cx43 increases serum induced filopodia formation via activation of p21-activated protein kinase 1. Biochim Biophys Acta 1853: 2907-2917.

8. Wang RA, Zhang H, Balasenthil S, Medina D, Kumar R (2006) PAK1 hyperactivation is sufficient for mammary gland tumor formation. Oncogene 25: 2931-2936.

9. Arias-Romero LE, Villamar-Cruz O, Pacheco A, Kosoff R, Huang M, et al. (2010) A Rac-Pak signaling pathway is essential for ErbB2-mediated transformation of human breast epithelial cancer cells. Oncogene 29: 5839-5849.

10. Roig J, Traugh JA (1999) p21-activated protein kinase gamma-PAK is activated by ionizing radiation and other DNA-damaging agents. Similarities and differences to alpha-PAK. J Biol Chem 274: 31119-31122.

11. Roig J, Huang Z, Lytle C, Traugh JA (2000) p21-activated protein kinase gamma-PAK is translocated and activated in response to hyperosmolarity. Implication of Cdc42 and phosphoinositide 3-kinase in a two-step mechanism for gamma-PAK activation. J Biol Chem 275: 16933-16940.

12. Tang TK, Chang WC, Chan WH, Yang SD, Ni MH, et al. (1998) Proteolytic cleavage and activation of PAK2 during UV irradiation-induced apoptosis in A431 cells. J Cell Biochem 70: 442-454.

13. Rudel T, Bokoch GM (1997) Membrane and morphological changes in apoptotic cells regulated by caspase-mediated activation of PAK2. Science 276: 1571 1574.

14. Rooney RD, Tuazon PT, Meek WE, Carroll EJ, Hagen JJ, et al. (1996) Cleavage arrest of early frog embryos by the $\mathrm{G}$ protein-activated protein kinase PAK I. J Biol Chem 271: 21498-21504.

15. Huang Z, Ling J, Traugh JA (2003) Localization of p21-activated protein kinase gamma-PAK/Pak2 in the endoplasmic reticulum is required for induction of cytostasis. J Biol Chem 278: 13101-13109.

16. Roig J, Traugh JA (2001) Cytostatic p21 G protein-activated protein kinase gamma-PAK. Vitam Horm 62: 167-198.

17. Jakobi R, McCarthy CC, Koeppel MA, Stringer DK (2003) Caspase-activated PAK-2 is regulated by subcellular targeting and proteasomal degradation. J Bio Chem 278: 38675-38685

18. Hsu YH, Johnson DA, Traugh JA (2008) Analysis of conformational changes during activation of protein kinase Pak2 by amide hydrogen/deuterium exchange. J Biol Chem 283: 36397-405.

19. Jakobi R, Moertl E, Koeppel MA (2001) p21-activated protein kinase gammaPAK suppresses programmed cell death of BALB3T3 fibroblasts. J Biol Chem 276:16624-1634

20. Wilkes MC, Mitchell H, Penheiter SG, Doré JJ, Suzuki K, et al. (2005) Transforming growth factor-beta activation of phosphatidylinositol 3-kinase is independent of Smad2 and Smad3 and regulates fibroblast responses via p21activated kinase-2. Cancer Res 65: 10431-10440.

21. Sato M, Matsuda Y, Wakai T, Kubota M, Osawa M, et al. (2013) P21-activated kinase- 2 is a critical mediator of transforming growth factor- $\beta$-induced hepatoma cell migration. J Gastroenterol Hepatol 28: 1047-1055.

22. Huang Z, Traugh JA, Bishop JM (2004) Negative control of the Myc protein by the stress-responsive kinase Pak2. Mol Cell Biol 24: 1582-1594.

23. Ling J, Morley SJ, Traugh JA (2005) Inhibition of cap-dependent translation via phosphorylation of elF4G by protein kinase Pak2. EMBO J 24: 4094-4105.

24. Orton KC, Ling J, Waskiewicz AJ, Cooper JA, Merrick WC, et al. (2004) Phosphorylation of Mnk1 by caspase-activated Pak2/gamma-PAK inhibits phosphorylation and interaction of elF4G with Mnk. J Biol Chem 279: 38649 38657. 
Citation: Ling J, Corneillie S, Cottell C, Traugh JA (2016) Activation of PAK2 by Serum Starvation Sensitizes its Response to Insulin Treatment in Adipocyte 3T3-L1 Cells. Biochem Anal Biochem 5: 277. doi:10.4172/2161-1009.1000277

Page 6 of 6

25. Tennant DA, Durán RV, Boulahbel H, Gottlieb E (2009) Metabolic transformation in cancer. Carcinogenesis 30: 1269-1280.

26. Schenk S, Saberi M, Olefsky JM (2008) Insulin sensitivity: modulation by nutrients and inflammation. J Clin Invest 118: 2992-3002.

27. Belardi V, Gallagher EJ, Novosyadlyy R, LeRoith D (2013) Insulin and IGFs in obesity-related breast cancer. J Mammary Gland Biol Neoplasia 18: 277-289.

28. Topisirovic I, Sonenberg N (2011) mRNA translation and energy metabolism in cancer: the role of the MAPK and mTORC1 pathways. Cold Spring Harb Symp Quant Biol 76: 355-367.

29. Gatti A, Huang Z, Tuazon PT, Traugh JA (1999) Multisite autophosphorylation of $\mathrm{p} 21$-activated protein kinase gamma-PAK as a function of activation. J Biol Chem 274: 8022-8028.

30. Ling J, Morley SJ, Pain VM, Marzluff WF, Gallie DR (2002) The histone 3'-terminal stem-loop-binding protein enhances translation through a functional and physical interaction with eukaryotic initiation factor 4G (elF-4G) and elF-3. Mol Cell Biol 22:7853-7867.

31. Hoffmann A, Levchenko A, Scott ML, Baltimore D (2002) The IkappaB-NFkappaB signaling module: temporal control and selective gene activation. Science 298: 1241-1245.

32. Lin L, DeMartino GN, Greene WC (1998) Cotranslational biogenesis of NFkappaB p50 by the $26 \mathrm{~S}$ proteasome. Cell 92: 819-828.

33. Higuchi M, Onishi K, Kikuchi C, Gotoh Y (2008) Scaffolding function of PAK in the PDK1-Akt pathway. Nat Cell Biol 10: 1356-1364.

34. Mao K, Kobayashi S, Jaffer ZM, Huang Y, Volden P, et al. (2008) Regulation of Akt/PKB activity by P21-activated kinase in cardiomyocytes. J Mol Cell Cardiol 44: 429-434.

35. Zhou GL, Zhuo Y, King CC, Fryer BH, Bokoch GM, et al. (2003) Akt phosphorylation of serine 21 on Pak1 modulates Nck binding and cell migration. Mol Cell Biol 23: 8058-8069.

36. Somanath PR, Byzova TV (2009) 14-3-3beta-Rac1-p21 activated kinase signaling regulates Akt1-mediated cytoskeletal organization, lamellipodia formation and fibronectin matrix assembly. J Cell Physiol 218: 394-404.

37. Sylow L, Jensen TE, Kleinert M, Højlund K, Kiens B, et al. (2013) Rac1 signaling is required for insulin-stimulated glucose uptake and is dysregulated in insulinresistant murine and human skeletal muscle. Diabetes. 62:1865-1875.

38. Tunduguru R, Chiu TT, Ramalingam L, Elmendorf JS, Klip A, et al. (2014) Signaling of the p21-activated kinase (PAK1) coordinates insulin-stimulated actin remodeling and glucose uptake in skeletal muscle cells. Biochem Pharmacol 92: 380-388.

39. Kalwat MA, Yoder SM, Wang Z, Thurmond DC (2013) A p21-activated kinase (PAK1) signaling cascade coordinately regulates $F$-actin remodeling and insulin granule exocytosis in pancreatic $ß$ cells. Biochem Pharmacol 85: 808-816.

40. Varshney P, Dey CS (2016) P21-activated kinase 2 (PAK2) regulates glucose uptake and insulin sensitivity in neuronal cells. Mol Cell Endocrinol 429: 50-61. 